\title{
God, the beautiful and mathematics: A response
}

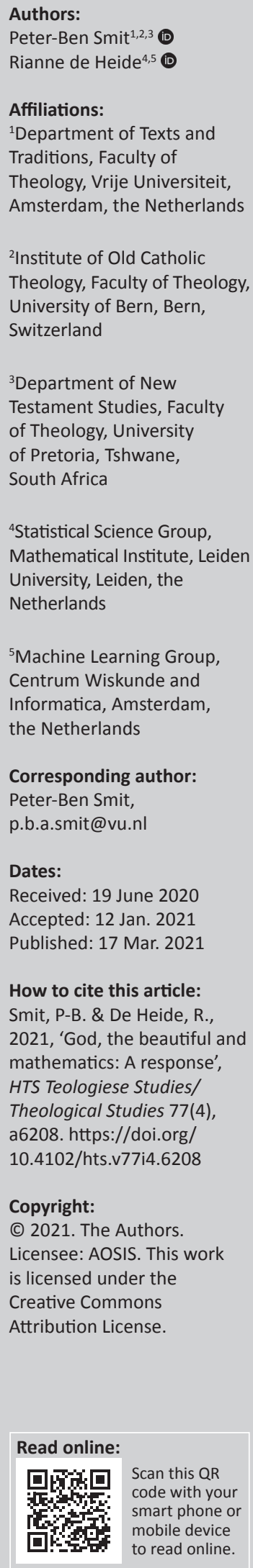

Volker Kessler ('God becomes beautiful ... in mathematics' - HTS 2018) argues two points to Rudolf Bohren's list of four areas where (1) God becomes beautiful should be extended with a fifth one: mathematics and (2) mathematics can be argued as a place where God becomes beautiful. In this response, we would like to argue that (1) the extension of Bohren's list that Kessler argues in favour of is superfluous and (2) that Kessler makes a number of questionable assumptions about (the philosophy of) mathematics. By arguing against Kessler, we intend to make an interdisciplinary contribution to the discussion about the relationship between mathematics and theology by pushing the debate into direction of a more careful consideration of mathematics as an area in which God's beauty may become apparent.

Contribution: Contributing to the interdisciplinary exploration of theology in HTS Teologiese Studies/Theological Studies, this article further develops the consideration of the fundamental theological topic of God, the beautiful and mathematics as it was proposed in this journal by Volker Kessler, by discussing it from a systematic theological and mathematical perspective.

Keywords: God; beautiful; culture; mathematics; philosophical underpinning.

\section{Introduction}

In his contribution 'God becomes beautiful ... in mathematics', Kessler (2018) argues that relation Rudolf Bohren's list of four areas where God's beauty (or rather: God's becoming beautiful in the creation through work of the Spirit) can be found should be extended with a fifth one: mathematics, in addition to creation, culture and arts, history and the church also mathematics can be seen as a place where God becomes beautiful, a proposal, which rests on an aesthetic interpretation of mathematics. In this response, we would like to argue that (1) the extension of Bohren's list that Kessler argues in favour of is superfluous (as is, in fact, indicated by himself) and (2) that Kessler makes a number of assumptions about (the philosophy of) mathematics that cannot be sustained when taking into consideration the current state of the field. The result of our consideration of Kessler's argument is an interdisciplinary contribution to the discussion about the relationship between mathematics and theology, which seeks to push the debate into direction of a more careful consideration of mathematics as an area in which God's beauty may become apparent in relation to other such areas, as far as theology is concerned, and a more precise treatments of mathematics, its philosophical underpinning and disciplinary self-understanding as such, which is a precondition for the crafting of any meaningful connection between it and other disciplines, such as theology.

\section{Four or five areas of God's beautification?}

Whether or not one should extend Bohren's helpful list of areas in which God may become beautiful - in the sense of becoming concrete, 'practical' - through the work of the Spirit - thereby overcoming the ugliness of sin in these various realms - depends on one's understanding of these areas, which seem to be consist of two pairs: nature and culture on the one hand and history and the 'Gemeinde' on the other. (1) When it comes to creation, Bohren emphasises the process of creation and the excess of beauty in creation, in particular: nature, on the one hand and God's justification of the beauty of creation (i.e. nature) on the other (i.e. by calling creation 'good'); yet, this is more than superficial romanticism or an attempt to provide proof for God's existence out of creation - it is all a question of faith and therefore about discerning God's becoming beautiful in the ongoing creation of nature, which can be seen as echoing God's own beauty liturgically (without ignoring ugliness and hurt that is also part of nature - here Bohren follows lines of thought of Teilhard de Chardin; cf. Bohren 1975:94-99). (2) In a similar way, Bohren understands God's beautification in human culture and art: 'Gottes Praktisch-Werden ist ein Schön-Werden in und durch die Schöpfung des Menschen, ist ein Schön-Werden in Kultur und Kunst' (Bohren 1975:100) In a sense, Bohren repeats here with regard to humankind what he has already said about the rest of creation; this agrees with the distinction between nature and culture in his list. (3) Regarding God's becoming beautiful in history, Bohren takes an overarching perspective on the history of the world that goes beyond human culture per se (one could argue, although, that the history of the 
world can be subsumed under the nature/culture categories or vice versa), indicating that also in the events of history, God's (salvific) becoming practical and beautiful can be discerned. (4) In analogy to the related realms of nature and culture, Bohren also treats the church ('Gemeinde') in relation to history: what can be said about the history at large can also be said about the particular of Israel and the Church, together God's 'Gemeinde', God's becoming practical in history cannot be reduced to God's working in the 'Gemeinde', yet it is also there and needs to be discerned in faith.

Based on this background, it becomes difficult to argue that mathematics should be a distinct field in which God becomes beautiful. The reason for this is quite simple: one would have to argue that mathematics is distinct from either the realm covered by the pair 'nature and culture' or by the pair 'history and Gemeinde'. That mathematics may not be part of the 'Gemeinde' would make sense - to a certain extent, at least that it is not a broader historical development would be hard to deny, however - even harder to deny is that mathematics is a distinctly human cultural achievement, which, depending on one's view of the matter, has to do with discovering the inner workings of nature and thereby of nature's beauty (as an echo of God's beauty or not).

In fact, it seems that this is also indicated by Kessler himself. As what has been argued in this section, in fact finds additional support in Kessler's (2018) own conclusions, where he states:

Thus, the mathematician contributes to the visibility of God's beauty in his creation. This would correspond with Bohren's viewpoint that God becomes beautiful in the creation (Bohren 1975:94-99). If, however, we follow the minority's viewpoint, namely that mathematics is a creation, then it would correspond with Bohren's chapter 'Culture and arts'. In that chapter, Bohren (1975:100) argues that God becomes beautiful by and through human creations in culture and arts. Thus, in both cases, we can conclude: God becomes beautiful in mathematics. (p. 6)

Depending on one's view of the achievement of a mathematician - discovering creation or creating something (cultural) - mathematics can be quite happily subsumed under one of Bohren's other categories, that is, either his first one (creation) or his second one (culture).

Therefore, a first and somewhat formal conclusion can be that the identification of mathematics as a distinct realm of God's becoming practical (in the sense of 'beautiful') is quite superfluous.

\section{Questions of mathematics and philosophy}

Kessler states 'In mathematics, there is a striking link between beauty and truth', and that 'mathematicians simply believe in truth', generalising from quotes of several more or less famous mathematicians. We will take a closer look at concepts that Kessler introduces, and see that the matter is more complicated than it might appear. The subject matter of Kessler's article gives rise to fundamental questions such as: 'what is mathematics about?', 'what is mathematical truth?', 'what do mathematical statements mean?', 'what is the source of mathematical knowledge?', etc. Some of these questions have been asked for many centuries, and are nowadays, after the substantial compartmentalisation of academia of the past century, being studied in the field of philosophy of mathematics.

In the following, we challenge two of Kessler's core ideas: first, the platonistic worldview of working mathematicians, which he takes as a point of departure in his argument. Secondly, we explore the apparent simplicity of the mathematical method: logical reasoning based on axiom systems, which is also of importance to Kessler. We take a closer look at complications that arise both with axiom systems and with logical reasoning, in order to illustrate further the complexity of mathematics, which needs to be considered when making arguments about mathematics and beauty.

Firstly, platonism amongst mathematicians will be considered. Mathematical platonism can be defined as holding the following three theses: (1) mathematical objects exist, (2) they are abstract and (3) they are independent of intelligent agents (Linnebo 2018). Let us start with one of Kessler's arguments in favour of a platonistic view of the mathematical world: natural language. Mathematicians often use the phrase: 'I discovered this theorem' (implying abstract existence of the theorem independent of the mathematician), although the parlance changes when talking about designing or inventing algorithms. The debate over the implicit meaning of using specific words to the mathematical worldview of the speaker is not novel: Plato himself already complained about the vocabulary of mathematicians writing about geometry (Plato, book 7 of Republic). Geometry is an interesting subject when we discuss thelanguagemathematicians use, which either would imply external existence of mathematical objects (discovery), or human creation (design, invention). As described in (Shapiro 2000:7), most sources of ancient geometry (including Euclid's Elements) use constructive, dynamic language. Today, we still talk about drawing lines, constructing angles, applying functions, rotating and translating figures. This speaks against a platonistic worldview.

Whilst it might be true that superficially, many mathematicians want to believe that the objects they study are real, Hersch (1979:32) famously states that they know better:

(...) The working mathematician is a platonist on weekdays and a formalist on Sundays. That is, when he is doing mathematics, he is convinced that he is dealing with an objective reality whose properties he is attempting to determine. But then, when challenged to give a philosophical account of this reality, he finds is easiest to pretend that he does not believe in it after all.

A study into the world views of university mathematics teachers, asking the 'Sunday question' (Grigutsch \& Törner 1998), confirms this. We do not disagree with Kessler that the platonic view (to be more precise: realism in ontology (Shapiro 2000)) is common amongst working mathematicians, but in Hersh' (1997) words, this is an 'inarticulate, halfconscious platonism', as it brings the mathematician in 
trouble when questions are asked how the platonic abstract world relates to our physical world. When asked these 'Sunday questions', mathematics reduces to rules for manipulating formulas without any reference to their meaning: Formalism, one of the 'Big Three' (Shapiro 2000) major philosophical positions in the past century (the other two being logicism and intuitionism). In other words, it is in appearance only that mathematicians are platonists, in reality, they are often formalists, in particular when they face the philosophical questions that one is forced to address when committing to a platonist position in the philosophy of mathematics. This strongly cautions against taking platonism as a representative point of departure in the philosophy of mathematics for making claims about the relationship between mathematics and theology.

Secondly, the concept of axiom systems is to be addressed. In his article, Kessler refers to the method of mathematics as starting with an axiom system, proceeding to further propositions by logical reasoning based on this axiom system - this is by the way a typical description of a formalistic approach. Such a system of axioms together with rules in order to generate new propositions (with additional conditions) is commonly referred to as a formal system. Kessler further writes that mathematical axiom systems are assumed not to give rise to contradictions, that is, they are assumed to be logically consistent (furthermore, Heisenberg is cited pointing to the coherence of axiom systems; coherence is usually characterised encompassing logical consistency). Such formal systems arose in the context of Hilbert's programme of providing a foundation for mathematics.

Kessler describes that his 'search for eternal, provable truth' led him to the discipline of mathematics and assumes that this is typical of mathematicians. If we combine this view with working with formal systems as a foundation for (the method of) mathematics, the following famous theorems of the mathematician and philosopher Gödel (1931) might come as a disappointment:

When $F$ is a consistent formal system (sufficiently rich, see Shapiro 2000 Ch.6.4), (1) there are statements in the language of $F$ that can neither be proved or disproved in $F$ (Gödel's first incompleteness theorem), and (2) the consistency of $F$ cannot be proved in $F$ itself (Gödel's second incompleteness theorem).

Gödel's two theorems show the limits of provability in axiomatic systems, which raises the question how 'eternal, provable truth' that can be reached via provability in some deductive system, can be compatible with Gödel's theorems. This depends on how we interpret Kessler's statement that his search for eternal, provable truth led him to mathematics, which we could view as realism in truth-value (Shapiro 2000). A truth-value realist, who views that every mathematical statement is objectively either true or untrue, would have to conclude that truth goes beyond provability in any axiomatic system, and the next question for the realist would be to define what this 'other type of truth' consists of. Much has been written about this since Gödel's publications in 1931, and it would be impossible to cover every point of view, our point here is merely to illustrate how much more there is to Kessler's casual mentioning of the deceptively uncomplicated reduction of truth-finding in mathematics to having consistent axiom systems together with logical reasoning see the upcoming paragraph. Again, Kessler's argument seems to be based on an oversimplified view of what mathematics and its philosophical reflection entails.

Finally, having said something about those axiom systems, it is possible to also address briefly what 'logical reasoning' is? The answer is more plural than one might expect. One of the Big Three (terminology of Shapiro [2000]) philosophical positions on mathematics is Intuitionism, and if one adheres to this view, it has extensive implications for one's practice of mathematics. The classical logic is replaced by an intuitionistic logic, which does not contain the law of the excluded middle: a law that states that for any proposition, either the proposition or its negation is true. Let us look at what happens with the indirect proof or reductio ad absurdum that Kessler brings up. Suppose we want to derive a contradiction from the proposition not-A, and we successfully conclude: not-not-A. The intuitionist cannot conclude the truth of A, whereas a classical logician can (illustrated by Kessler's example of the existence of infinitely many primes). So also the matter of what logic we should use when we do mathematics turns out to be more complicated than Kessler makes it appear.

When only considering mathematics superficially, it seems to be this very clear-cut discipline where objective truth follows from well-defined axiom systems and logical deductions. Here, we have shown that when we take a closer look, many questions and problems arise; problems that have been considered by many mathematicians and philosophers of mathematics in the history - ancient and recent. Our findings are by no means novel, see for example (Ernest 2016), who concludes that 'mathematical certainty is a myth'.

\section{Concluding observations}

In the given considerations of Kessler's argument, we have engaged in a debate with Volker Kesser and his contribution to the relationship between mathematics and theology, in particular the aesthetic proposal for a practical theology of Rudolf Bohren. In doing so, we have argued, as a contribution to furthering reflection on the relationship between these two disciplines, that (1) the addition of mathematics as a fifth area where God's beauty can become apparent is not necessary, given that mathematics can well be seen as being covered by one or two of Bohren's other areas, and (2) that Kessler does not discuss in detail the current state of research in the field of philosophy of mathematics, and in not doing so, the view of mathematics in his article is not sufficiently represented to function as a starting point for crafting a bridge between this and other disciplines. Research into the relationship between theology and mathematics remains inviting but it would be necessary to do so on the basis of the full inclusion of current positions in the philosophy of mathematics and in a manner that more fully considers the relationship between mathematics and human culture and history, at least when a connection is to be established with Bohren's paradigm. 


\section{Acknowledgements}

Competing interests

The authors have declared that no competing interests exist.

\section{Authors' contribution}

All authors contributed equally to this work.

\section{Ethical considerations}

This article followed all ethical standards for a research without direct contact with human or animal subjects.

\section{Funding information}

This research received no specific grant from any funding agency in the public, commercial or not-for-profit sectors.

\section{Data availability}

Data sharing is not applicable to this article as no new data were created or analysed in this study.

\section{Disclaimer}

The views and opinions expressed in this article are those of the authors and do not necessarily reflect the official policy or position of any affiliated agency of the authors.

\section{References}

Bohren, R., 1975, Dass Gott schön werde: Praktische theologie als theologische Ästhetik, Kaiser, München.

Ernest, P., 2016, 'The problem of certainty in mathematics', Educational Studies in Mathematics 92(3), 379-393. https://doi.org/10.1007/s10649-015-9651-x

Gödel, K., 1931, 'Über formal unentscheidbare Sätze der Principia Mathematica und verwandter Systeme I', Monatshefte für Mathematik und Physik 38, 173-198, English translation in: Idem, Collected works I: Publications 1929-1936, pp. 144-195, Oxford University, Oxford, 1986. https://doi.org/10.1007/BF01700692

Grigutsch, S. \& Törner, G., 1998, World views of mathematics held by university teachers of mathematics science, Fachbereich Mathematik, UD.

Hersh, R., 1979, 'Some proposals for reviving the philosophy of mathematics', Advances in Mathematics 31(1), 31-50. https://doi.org/10.1016/0001-8708(79)90018-5

Hersh, R., 1997, What is mathematics, really?, Oxford University Press, Oxford.

Kessler, V., 2018, 'God becomes beautiful ... in mathematics', HTS Teologiese Studies/ Theological Studies 74(1), a4886. https://doi.org/10.4102/hts.v74i1.4886

Linnebo, Ø., 2018, 'Platonism in the philosophy of mathematics', in E.N. Zalta (ed.), The Stanford encyclopedia of philosophy, Spring 2018 edition, viewed March 2020, from https://plato.stanford.edu/archives/spr2018/entries/platonism-mathematics.

Shapiro, S., 2000, Thinking about mathematics: The philosophy of mathematics, Oxford University Press, Oxford. 